\title{
Investigation of Preliminary Student Test Performance Data Using the ANOM Statistical Tool and Mixed Model Analysis
}

\author{
Anja Habus-Korbar ${ }^{1}$, Vesna Lužar-Stiffler ${ }^{2,3}$ and Vanda Bazdan ${ }^{1}$ \\ ${ }^{1}$ National Center for External Evaluation of Education, Zagreb, Croatia \\ ${ }^{2}$ University Computing Centre - Srce, University of Zagreb, Croatia \\ ${ }^{3}$ CAIR Center, Zagreb, Croatia
}

\begin{abstract}
The goal of this paper is to demonstrate the analytical use of a statistical tool ANOM (more commonly used by quality control engineers), mixed model analysis and other statistical tools (used in social sciences) to investigate differences found in Croatian high school student performance in mathematics examinations, recently developed as part of the National Assessment project.
\end{abstract}

Keywords: National Assessment, analysis of means, ANOM, mixed models, Shewhart procedure, mathematics scores

\section{Introduction}

This research is based on the results of the $\mathrm{Na}-$ tional Assessment in mathematics organized by the National Center for External Evaluation of Education (NCVVO). The objective and function of NCVVO (among others) is to monitor and evaluate the global and regional performance of students in order to improve the quality of the Croatian educational system. The National Assessment is a testing procedure conducted on high school students with the goal of learning more about student knowledge and the educational system. It also serves as a precursor for students and teachers concerning the final high school exam which will be (in future years) held as a standardized, uniform test.

The paper is divided into seven sections: After the introduction and background of the National Assessment project, Section 3 concentrates on the description and history of the ANOM procedure. In Section 4 we present the global descriptive statistics and the distribution of scores (globally and also by programs and by different counties). The Shewhart procedure was used for visualization of the differences among programs and counties. In Section 5, we cover the results obtained from three-way analysis of variance. After detecting the differences among different programs and counties it was reasonable to suspect that the interactions among these factors might be significant. Section 6 illustrates the use of the ANOM procedure for two-way effects, applied due to the results of previous analysis. For the final analysis, in Section 7, a mixed model (with schools and classes as random, nested effects) was developed.

\section{Background}

The survey was carried out on a random sample of size 2664, $2^{\text {nd }}$ grade students attending Croatian gymnasium programs.

The data were collected through the National Exam in mathematics, conducted at the beginning of the second semester (February, 2007). It had two goals: (1) to see how well the students were performing in general and (2) to investigate if significant differences existed in performance of students living in different parts of the country (21 Croatian counties) and also to 
observe if differences existed for different gymnasium programs. In Croatian schools there are four types of gymnasium programs: general, language, mathematics and classical. The final test results for all subjects and across different counties, programs and schools were presented to the general public.

In this paper we focus only on the data available at the time and the statistical methodology used to detect key differences among different groups of high school students.

\section{Analysis of Means (ANOM)}

After applying standard procedures for describing the data, the Shewhart procedure for visualizing performance across different groups and the three-way ANOVA to test for significant effects and interactions, it was necessary to select a procedure which would test for any difference between means of the different programs (distinguish above-average programs from those which are at or below the average). Above all, the results had to be easy to interpret for most of the general public.

Originally studied by Laplace in 1827, Analysis of Means has become a common approach to identifying any group that is performing differently from the rest.

It compares the absolute deviations of group means from their overall mean. Halperin and others derived a version of this method in the form of a multiple significance test in 1955. Ott developed a graphical representation for the test and introduced the term "analysis of means" in 1967. Refer to Ott (1967).

P. R. Nelson (1982) introduced exact critical values for ANOM when the groups have equal sample sizes and (also in 1991) developed a method for computing exact critical values for ANOM when group sample sizes are not equal.

Unlike ANOVA, which tests for significant difference among the group means, Analysis of Means identifies those means which are significantly different from the overall (or grand) mean.

The ANOM is a type of multiple comparison procedure. The results of the analysis are summarized in an ANOM decision chart. This chart is similar in appearance to a control chart. It has a centerline, located at the overall mean (rate or proportion) and upper and lower decision limits. Group means (or rates or proportions) are plotted on this chart and if one falls beyond a decision limit, then that group is said to be statistically different from the overall mean (rate or proportion). Practical as well as statistical significance can be easily assessed. It is easy to understand, and sheds light on the nature of the differences among the populations.

The underlying model assumptions for ANOM are the same as for fixed effects ANOVA - independent random samples from normal populations with homogeneous variances.

\section{Data and Descriptive Statistics}

Prior to the analysis, each student score was divided by the highest possible score (maximum) to yield a percent maximum score. In other words, we used a relative scale ranging from 0 to 100 . (Note: Test validity and reliability analyses were performed, but are not part of this presentation.)

\subsection{Data Distribution}

The distribution (of percent maximum mathematics score) is close to normal with skewness of 0.35 and kurtosis of -0.7 . Since the sample size was large $(n=2664)$ we could perform further analysis, even though the assumption of the normal distribution was not met. The mean score was $45 \%$, median was slightly lower $(43 \%)$. Standard deviation was approximately $22 \%$, which is substantially higher than standard deviations for the other exams (Croatian and English percent maximum test scores each had a standard deviation of approximately 15). The distribution is shown in Figure 1.

\subsection{The Shewhart procedure}

Furthermore, differences in achievement among the four gymnasium programs can be seen in Figure 2. Each program (represented by one of the four boxplots) is positioned relative to the global overall mean. If the mean of the group (represented by a cross) is above the upper control limit for the global mean, the group's performance is considered above the average. If it is below the lower control limit for the overall mean, it is considered below the average. 


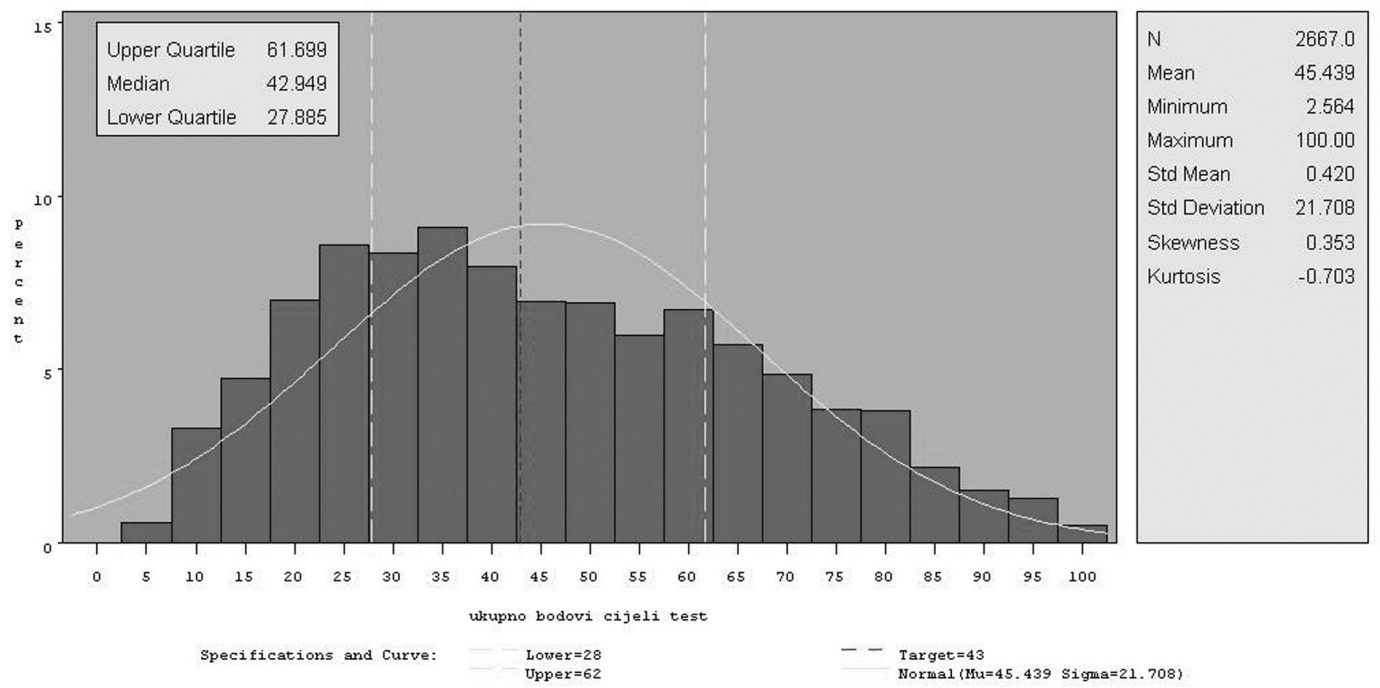

Figure 1. Distribution of scores (expressed as percent maximum score) on the National Exam in mathematics.

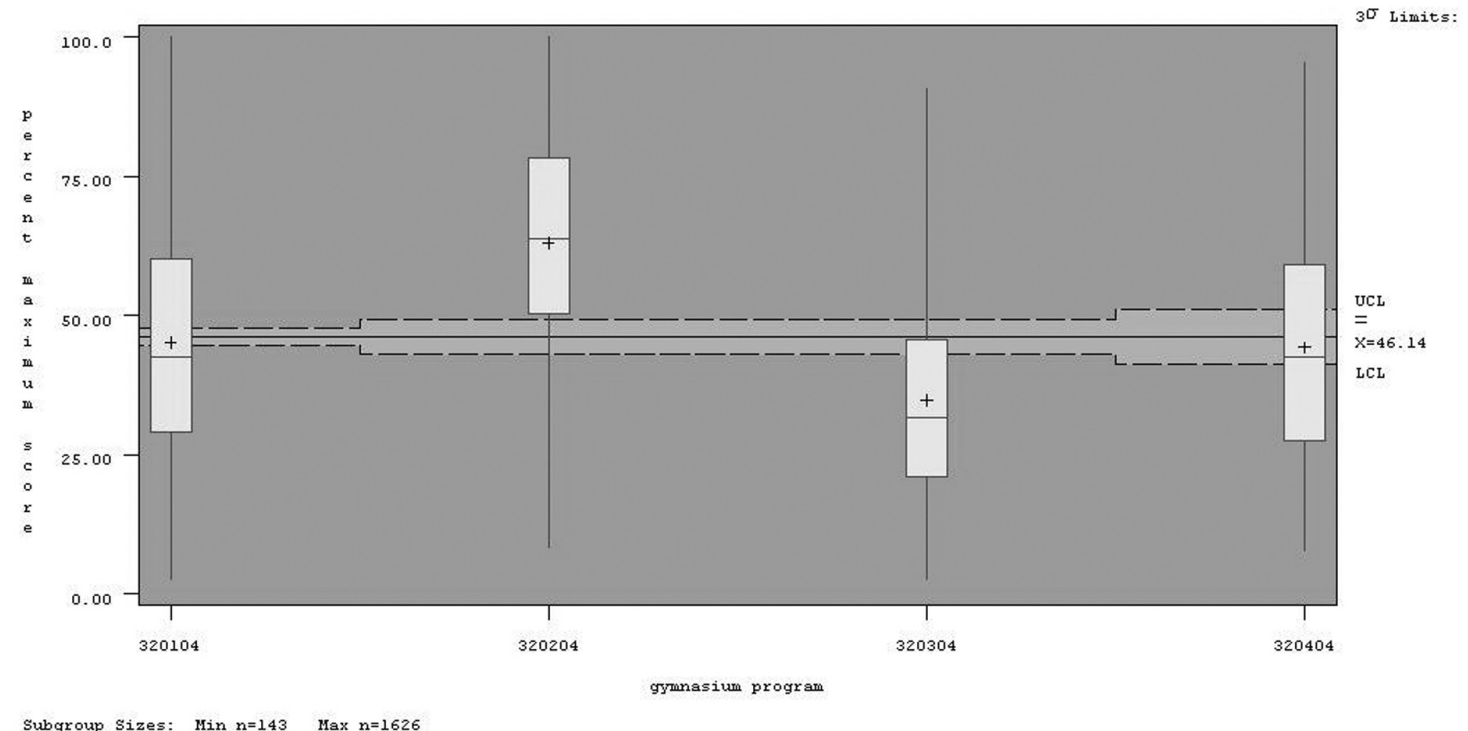

Figure 2. Differences in achievements among four gymnasium programs.

The control limits are automatically adjusted to the varying group sizes. The legend at the bottom of Figure 2 reports the minimum and maximum group sizes (min. $n=143$, max. $n=1626$ ).

From the Figure, we can see that the mean of the program labeled 320204 (indicating mathematical gymnasiums) is significantly above the overall mean. Since the lower line on the boxplot represents 1st quartile, we could say that about $75 \%$ of the mathematical gymnasium students scored above the global mean. On the other hand, the mean score of students attending the program labeled 320304 (indicating language gymnasiums) is significantly below the global mean with about $75 \%$ of scores falling below the lower control limit for the global mean.

Additionally, from Figure 3 we can see that the results are not uniformly distributed across counties either. The number of students also varies across the counties (e.g., in district 9 the number is three times lower than the number of students in an average sized county). 


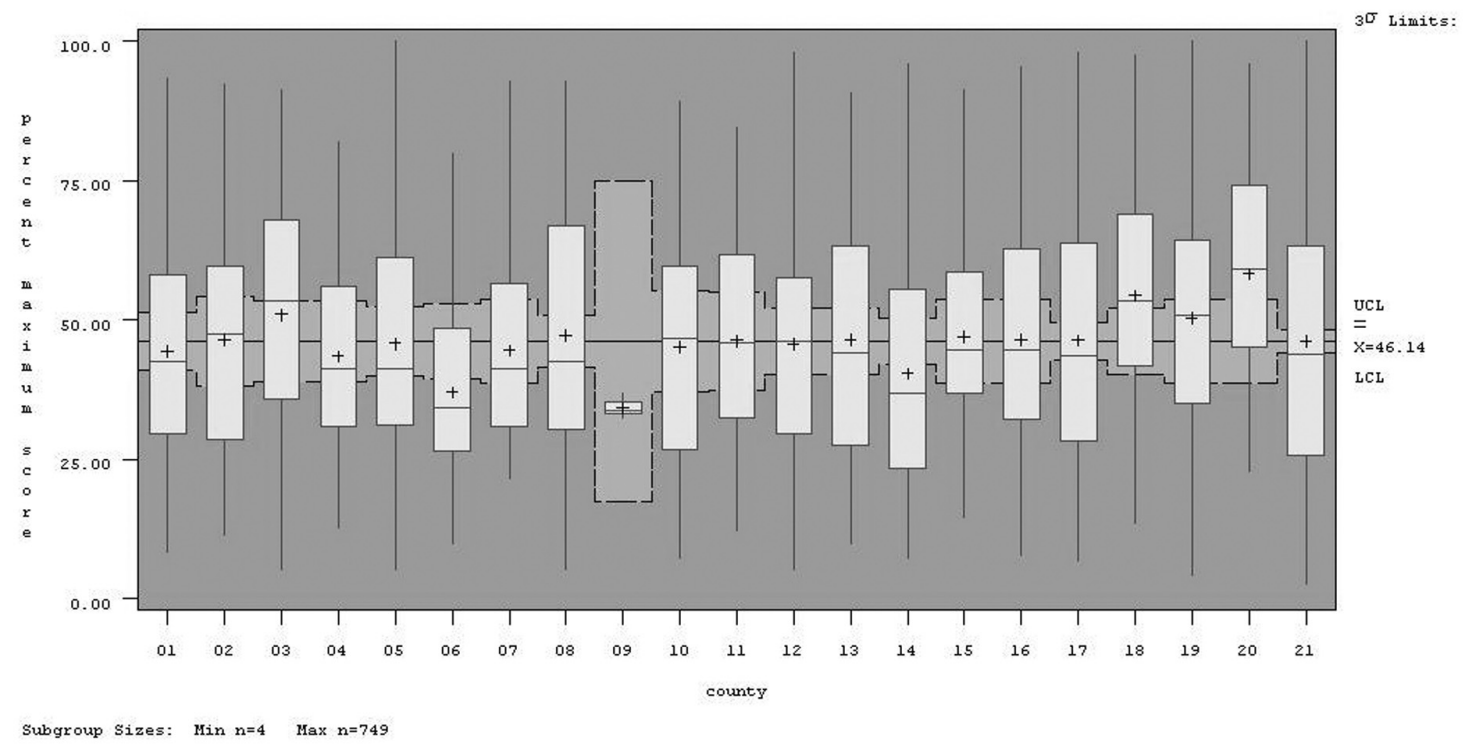

Figure 3. Differences in achievements among 21 Croatian counties.

\section{Three-way Analysis of Variance}

In further analysis we used a three-way analysis of variance to test for the differences among counties, programs and also school sizes.

For school size we used (for this analysis) a binary variable ("small"/"large"), with "small" category representing schools with 100 or less students and "large" indicating those schools that had more than 100 students. The analysis yielded all three significant main effects, which confirmed previous results, indicating that mathematics test scores differed both by the program and by region. Small and large schools performed differently as well, larger schools demonstrating significantly higher achievement. Significant interactions were found between county and program $(\mathrm{F}=3.45 \mathrm{p}<0.001)$, between county and school size $(\mathrm{F}=5.59$ $\mathrm{p}<0.001)$ and between program and size $(\mathrm{F}=7.99 \mathrm{p}<0.001)$. These results indicate that programs do differ, but these differences are contingent on the county and also on school size. The above model explains $24 \%$ of variability $\left(\mathrm{R}^{2}=0.24\right)$. The interactions among county and program are visualized in Figure 4.

Blue line (squares) shows mean scores of mathematical gymnasiums by county; yellow (circles) and green line (triangles) represent general and language mean program scores, respec-

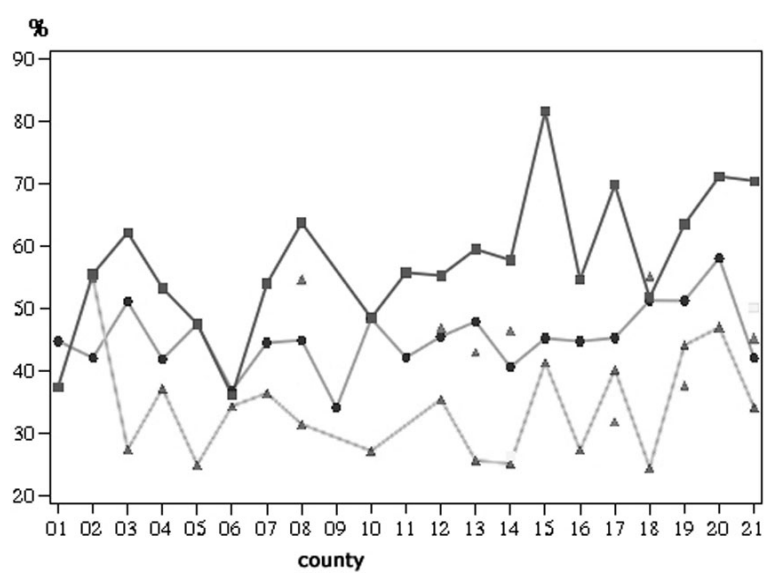

Figure 4. Line plot (connecting means) showing the interactions among programs and counties.

tively. Classical gymnasium (not available in all counties) average results are shown using purple triangles (not connected with a line). This graphical display allows us to see the differences analyzed previously. From the line plot we cannot see which programs and counties achieved significantly higher results.

\section{The ANOM Procedure}

For a further and more detailed graphical display and due to the results of the previous analysis, which indicate that programs differ (but rel- 


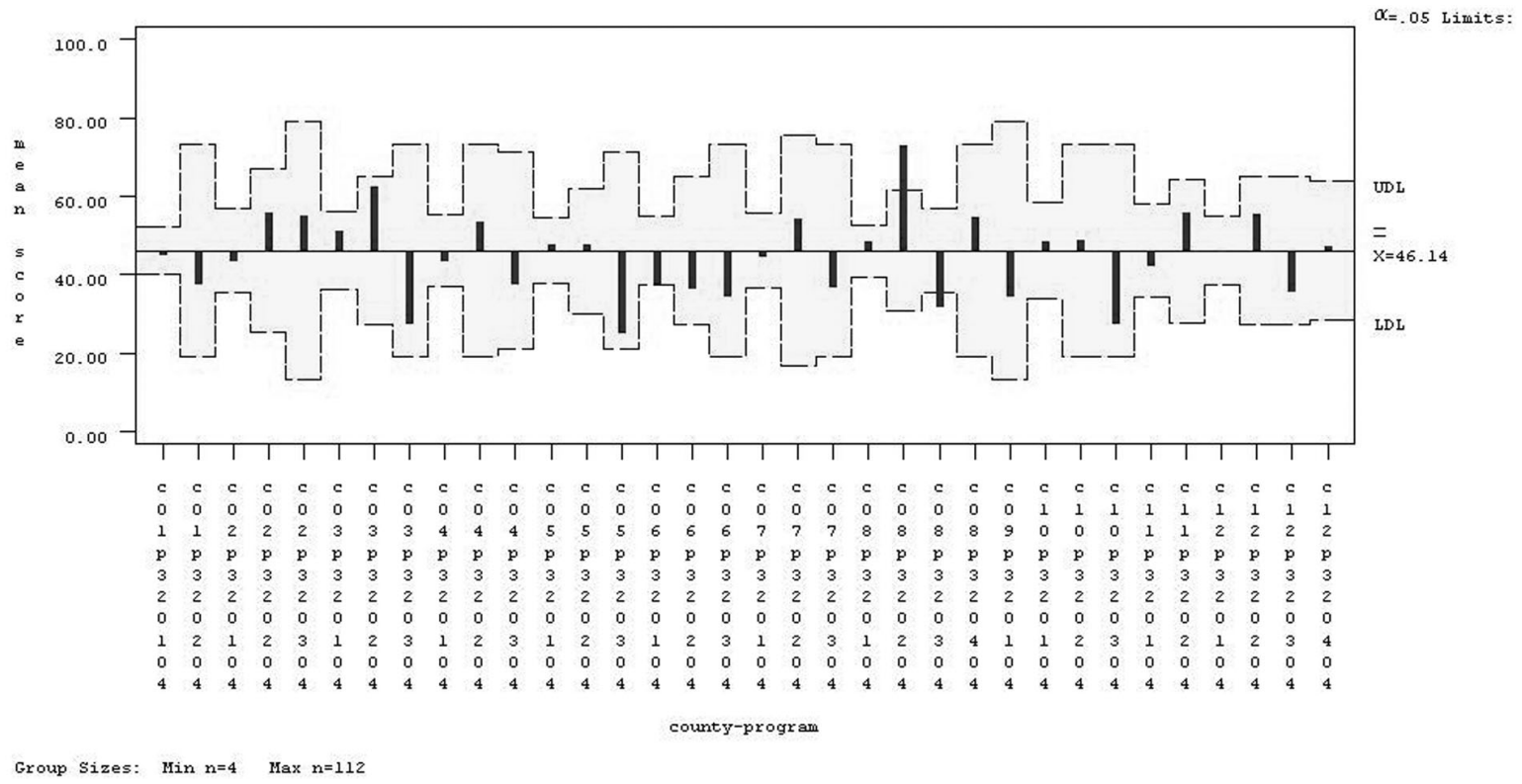

Figure 5a. ANOM procedure chart.

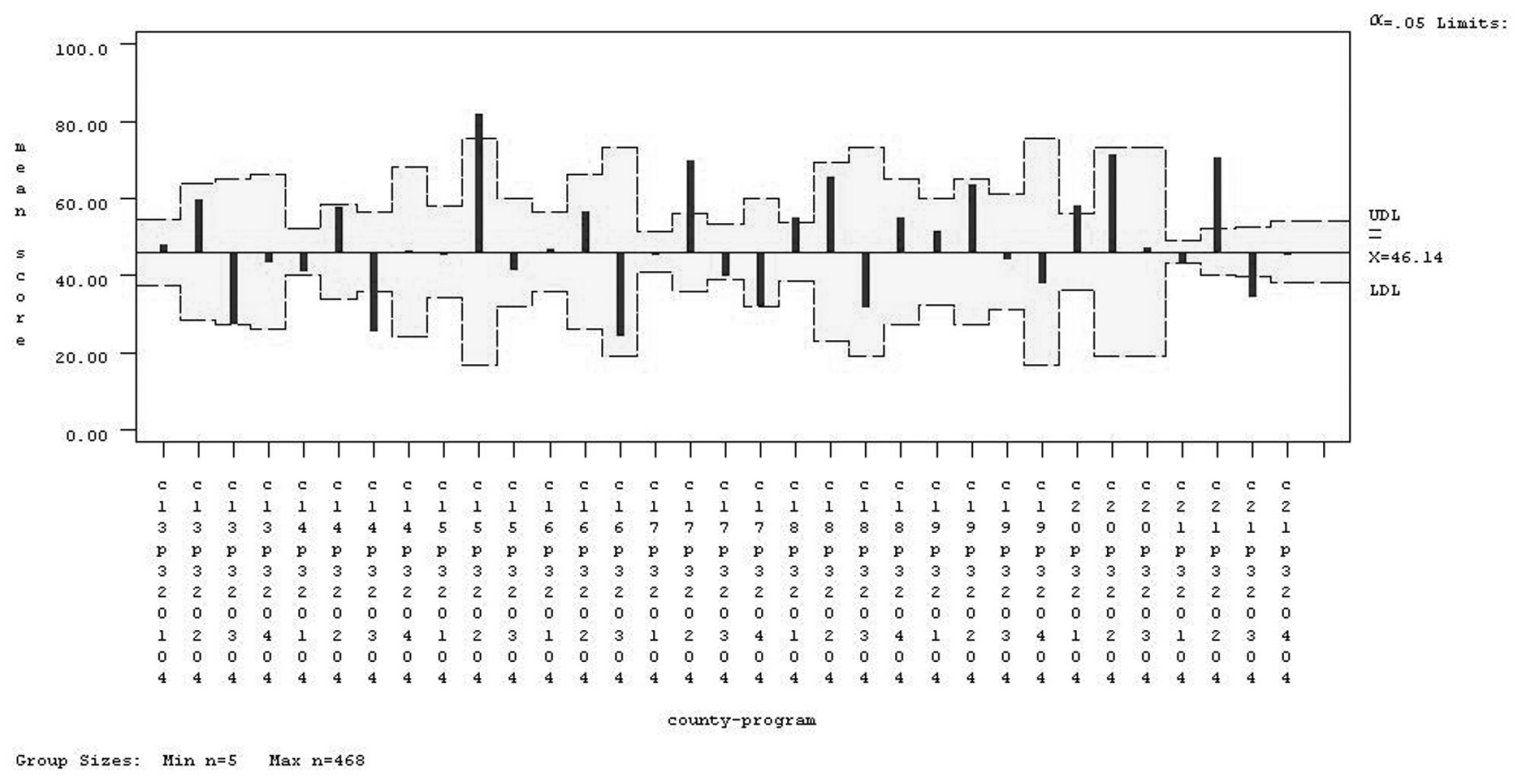

Figure 5b. ANOM procedure chart (continued).

ative to the county), we used the ANOM procedure for significant two-way effects. The results by county and program are shown in Figures $5 \mathrm{a}$ and $5 b$.

The yellow field (dash lines) shows the confidence interval (around the global mean). The confidence interval is different across different counties and programs, due to different number of students and the variability. If the group's mean falls above/below the confidence interval it is considered significantly better/worse than the average. We can see that, even though the results of Mathematical gymnasiums (320204) were globaly significantly above average, this is not the case in all counties. In counties $1,2,3,4,5,6,7,10,11,12,13,14,16$ the results were average and only counties $8,15,17,18,20$ and 21 showed significantly better results than the average. Also, a significantly better result was achieved by students in general gymnasium (320104) in county 18. 


\begin{tabular}{|l||r|r|r|r|r|r|}
\hline \multirow{2}{*}{ Significantly different county-program } & \multirow{2}{*}{$\begin{array}{l}\text { Group } \\
\text { Sampe }\end{array}$} & \multicolumn{3}{|l|}{ Alpha=.05 Limits for Mean (Adjusted for multiple testing) } \\
\cline { 5 - 8 } & Size & $\begin{array}{c}\text { Lower } \\
\text { Limit }\end{array}$ & $\begin{array}{c}\text { Group } \\
\text { Mean }\end{array}$ & $\begin{array}{c}\text { Average } \\
\text { Mean }\end{array}$ & $\begin{array}{c}\text { Upper } \\
\text { Limit }\end{array}$ & $\begin{array}{c}\text { Limit } \\
\text { Exceeded }\end{array}$ \\
\hline \hline County 08, Mathematics gymnasium & 18 & 30.63 & 72.76 & 46.15 & 61.65 & Upper \\
\hline County 08, Language gymnasium & 38 & 35.51 & 31.52 & 46.15 & 56.77 & Lower \\
\hline County 14, Language gymnasium & 41 & 35.91 & 25.22 & 46.15 & 56.37 & Lower \\
\hline County 15, Mathematics gymnasium & 5 & 16.64 & 81.57 & 46.15 & 75.65 & Upper \\
\hline County 17, Mathematics gymnasium & 42 & 36.04 & 69.78 & 46.15 & 56.25 & Upper \\
\hline County 17, Classical gymnasium & 22 & 32.13 & 31.86 & 46.15 & 60.16 & Lower \\
\hline County 18, General gymnasium & 71 & 38.42 & 54.94 & 46.15 & 53.87 & Upper \\
\hline County 20, General gymnasium & 45 & 36.39 & 58.08 & 46.15 & 55.90 & Upper \\
\hline County 21, General gymnasium & 468 & 43.39 & 42.72 & 46.15 & 48.90 & Lower \\
\hline County 21, Mathematics gymnasium & 118 & 40.21 & 70.42 & 46.15 & 52.08 & Upper \\
\hline County 21, Language gymnasium & 99 & 39.64 & 34.28 & 46.15 & 52.652 & Lower \\
\hline
\end{tabular}

Table 1. County-programs scoring significantly better/worse than the average.

As part of the output of the $\mathrm{SAS}^{1}$ ANOM procedure, means chart summary (shown in Table 1) can be obtained with the results for each group that is above or below the average. All data preparation, analyses, graphics and tabulation for the current study were performed using SAS software (licenced to NCVVO).

\begin{tabular}{|l||r|}
\hline Cov Parm & Estimate \\
\hline \hline School(County) & 100.48 \\
\hline Class(County*School) & 27.2344 \\
\hline Residual & 292.50 \\
\hline
\end{tabular}

Table 2. Covariance Parameter Estimates.

\begin{tabular}{|l||r|r|r|r|}
\hline Effect & $\begin{array}{c}\text { Num } \\
\text { DF }\end{array}$ & $\begin{array}{c}\text { Den } \\
\text { DF }\end{array}$ & $\begin{array}{c}\text { F } \\
\text { Value }\end{array}$ & Pr $>$ F \\
\hline \hline Size & 1 & 2224 & 0.86 & 0.3551 \\
\hline County & 20 & 78 & 1.04 & 0.4308 \\
\hline Program & 3 & 2224 & 4.41 & 0.0042 \\
\hline Size*County & 16 & 2224 & 1.38 & 0.1440 \\
\hline Size*Program & 3 & 2224 & 5.25 & 0.0013 \\
\hline County*Progr. & 43 & 2224 & 1.48 & 0.0227 \\
\hline
\end{tabular}

Table 3. Type 3 Tests of Fixed Effects.

\section{The Mixed Model Analysis}

For the final analysis we applied SAS MIXED (mixed model) procedure. Program, county, size of the school and the interactions were treated as fixed effects (as in the previous analysis). School (within county) and class (within school and county) were treated as random effects. The results are shown in Tables 2-4. Under the "Covariance Parameter Estimates" in Table 2 the estimates are displayed of random effects variances and the residual variance, $\sigma^{2}$. (As was previously mentioned, this was a random sample of $n=2664$.)

As expected, mixed model analysis yielded slightly more conservative results than the previously performed three-way ANOVA. From the results displayed in Table 3, we see that out

\begin{tabular}{|l|r|r|r|r|}
\hline Program & $\begin{array}{c}\text { Num } \\
\text { DF }\end{array}$ & $\begin{array}{c}\text { Den } \\
\text { DF }\end{array}$ & $\begin{array}{c}\text { F } \\
\text { Value }\end{array}$ & Pr $>$ F \\
\hline \hline General gynasium & 16 & 2224 & 1.20 & 0.2559 \\
\hline Mathematics gynasium & 16 & 2224 & 1.89 & 0.0173 \\
\hline Language gynasium & 14 & 2224 & 1.24 & 0.2363 \\
\hline Classical gynasium & 6 & 2224 & 1.46 & 0.1878 \\
\hline
\end{tabular}

Table 4. Simple effect tests of difference among counties for each program separately.

\footnotetext{
${ }^{1}$ SAS is a registered trademark of SAS Institute, Inc., NC, USA.
} 
of three main effects (Size, County, Program) only Program is significant $(\mathrm{F}=5.25 \mathrm{p}<0.001)$. As it might have been expected, interactions were significant between county and program $(\mathrm{F}=1.48, \mathrm{p}=0.02)$ and between program and school size $(\mathrm{F}=5.59, \mathrm{p}=0.001)$.

These results confirm (the outcome of the other analyses described in this paper) that the Mathematics scores are different across different gymnasium programs and that the differences among the counties are not the same for all programs. Additionally, the differences among programs are not the same in "small" as in "large" schools. If we examine Table 4 (for the test of differences among counties for each program separately) we can see that the only program where significant differences were found across counties is the Mathematical gymnasium program.

\section{Conclusion}

Several analyses were conducted using the currently available data on student achievement in Mathematics. Analysis of variance results showed that Mathematics scores are on average significantly different across regions, programs and school sizes. Analysis of means (ANOM) was used to identify and visualize the differences among those individual programs/counties in which students achieved results that were significantly better/worse than the average. We showed that, even though the results of Mathematical gymnasiums were globally significantly above the average, this was not the case in all counties.

The final, mixed model analysis, in which we considered school and class as random (and nested) effects, gave more conservative results. We conclude that mathematics scores differ among programs, with only the mathematics program showing significant differences across the counties.

The main disadvantage of the analyses presented in this research is the inability to control for possible confounding variables (student socio-economic status, data on teachers and schools, etc.), data on which are currently being collected.

Once this additional information becomes available, less biased estimations and comparisons of student performance will be possible. Additionally, a program of longitudinal studies for continuous measuring and monitoring of student achievement in a number of subject areas over a period of at least five years should be planned and implemented.

\section{References}

[1] P. R. Nelson, (1982), Exact Critical Points for the Analysis of Means. Communications in Statistics Theory and Methods, 11(6), pp. 699-709.

[2] P. R. Nelson, (1983), A Comparison of Sample Sizes for the Analysis of Means and the Analysis of Variance. Journal of Quality Technology, 15, pp. 33-39.

[3] P. R. Nelson And E. J. Dudewicz, (2002), Exact Analysis of Means with Unequal Variances. Technometrics, 44, pp. 152-160.

[4] E. R. OTт, (1967), Analysis of Means - A Graphical Procedure. Industrial Quality Control, 24, pp. 101-109.

[5] W. L. Sanders, A. M. SaXton and S. P. Horn, (1997), The Tennessee Value-added Assessment System: A Quantitative Outcomes-based Approach to Educational Assessment. In J. Millman (Ed.), Grading Teachers, Grading Schools: Is Student Achievement a Valid Educational Measure? Thousand Oaks, CA: Corwin Press. pp. 137-162.

[6] S. P. Wright, (2004), Advantages of a Multivariate Longitudinal Approach to Educational Value-added Assessment without Imputation. Paper presented at the National Evaluation Institute, Colorado Springs, $\mathrm{CO}, \mathrm{USA}$

Received: June, 2008 Accepted: September, 2008

Contact addresses:

Anja Habus-Korbar National Center for External Evaluation of Education Marulićev trg 18 10000 Zagreb, Croatia e-mail: anjahk@ncvvo.hr

Vesna Lužar-Stiffler, PhD University of Zagreb University Computing Centre J. Marohnića 5 10000 Zagreb, Croatia e-mail: vluzar@srce.hr Marulićev trg 18 10000 Zagreb, Croatia e-mail: vanda.bazdan@ncvvo.hr 
ANJA HABUS-KORBAR, after finishing elementary and high school education in Croatia, USA and Italy, graduated from the Faculty of Veterinary Medicine at the University of Zagreb. She is currently completing her postgraduate study at the Faculty of Science, Department of Biology (with the thesis in the area of data mining, using the data from the field of anthropology) at the University of Zagreb. After a few years with the pharmaceutical company Merck, she moved to the field of educational statistics and IT and is currently working at the National Center for External Evaluation of Education.

VESNA LUŽAR-STIFFLER is a senior researcher at the University Computing Centre, University of Zagreb and the Director of Statistical Methods at CAIR Research Center in Zagreb, Croatia. She obtained her B.Sc. in mathematics, and her Ph.D. in computer science / computational statistics from the University of Zagreb, and was awarded a Fulbright Postdoctoral Grant for research at the Department of Statistics, Stanford University, specializing in computational statistics and multivariate analysis. Her research interests include visualization methods in data mining and computational statistics. She has been chairing the International Program Committee of the ITI (Information Technology Interfaces) Conference since 2004. For the past twenty years she has taught a broad range of software-aided statistics and data mining courses at the University Computing Centre, University of Zagreb, Stanford University, University of Maryland, University of Naples, University of Neuchatel (postgraduate study in statistics), SAS Institute, and at many government and business / industry institutions. Dr. LužarStiffler has consulted in the area of statistical / graphical / data mining application, clinical trials, marketing research, survey sampling, risk assessment and quality improvement with various companies (including pharmaceutical, banking, aeronautic, automotive, semiconductor manufacturing technology, insurance, food retail, beverage, telecommunications) and government organizations in the US, Italy, Croatia, Slovenia, Macedonia, Romania, BiH, etc.

VANDA BAZDAN has a B. Sc. degree in sociology obtained from the University of Zagreb. She is currently employed in R\&D Department at the National Center for External Evaluation of Education. 